\title{
Nonhomogeneous force application during typical flutter ablation explains local difficulties in lesion creation
}

Decebal Gabriel Latcu', Bogdan Enache',2, Nazih Benhenda', Dragos Cozma², Ruben Casado-Arroyo ${ }^{3}$, Frédéric Anselme ${ }^{4}$, Atul Pathak', Nadir Saoudi'

\begin{abstract}
Introduction - The current scientific literature suggests similar or even better catheter contact on caval regions of the cavo-tricuspid isthmus (CTI) compared to the more medial or annular part. Yet CTI ablation can be challenging owing to instability at the inferior vena cava (IVC) edge. No study specifically addressed the issue of catheter-tissue contact on caval/mid/annular regions of the CTI. Methods - Twenty-seven patients ( 22 men, $67 \pm 12$ years) underwent typical atrial flutter ablation with a contact force (CF) sensing catheter (Tacticath 75 , Abott) and were prospectively included. Operators aimed at optimizing CF for all RF pulses. The product of CF, time (force-time integral; FTI) and delivered power (FTPI) has been proposed as an estimate of lesion size. In a subset of 8 consecutive pts, electrograms (EGM) of all RF lesions were analyzed. Annular CTI was defined as sites showing both atrial and ventricular near-field bipolar EGM. Mid CTI sites had only atrial near field bipolar EGM on both distal and proximal dipoles (or distal only in case of superior-to-inferior approach). Caval sites had near-field bipolar EGM only in distal dipole, while the proximal one was inferiorly located. Results - Complete persistent (at $30 \mathrm{~min}$ ) CTI block was obtained in all patients. A steerable sheath was used in 12 pts (44\%). Procedure duration was $93 \pm 30 \mathrm{~min}$, RF delivery time $10 \pm 6 \mathrm{~min}$, fluoroscopy time $14 \pm 8 \mathrm{~min}$. Mean CF was $15.8 \pm 5.9 \mathrm{~g}$. CF was signifi-

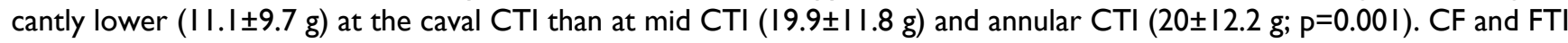
were higher during sinus rhythm than during $\mathrm{FI}(23.2 \pm 15.3$ vs $18.5 \pm 15.4 \mathrm{~g}, \mathrm{p}=0.04$ and $677 \pm 432$ vs $532 \pm 357 \mathrm{gs}, \mathrm{p}=0.03)$. Use of a sheath improved mean CF $(24.4 \pm 12.5$ vs $18.4 \pm \mid 4.9 \mathrm{~g}, \mathrm{p}=0.0 \mathrm{I})$ but this was not significant at caval sites $(17.5 \pm$ II.4 vs $12.6 \pm 10.7 \mathrm{~g}, \mathrm{p}=0.3 \mathrm{I})$. Conclusion - Applied forces are significantly lower at the IVC edge during CTI ablation. This supports the use of a steerable sheath in challenging cases.
\end{abstract}

Keywords: atrial flutter, contact force, cavo-tricuspid isthmus.

\section{INTRODUCTION}

Experimental data shows that the quality of the electrode-tissue contact (the contact force; CF) is a major determinant of the depth/size of RF lesions ${ }^{1,2}$. For that reason CF-sensing catheters became the gold standard in complex ablations ${ }^{3,4}$.

Typical atrial flutter (AFL) and its ablation were, before the rise of atrial fibrillation ablation, the subject of extensive research. While in the last decade pu-

\footnotetext{
' Centre Hospitalier Princesse Grace, Monaco, France

${ }^{2}$ „Victor Babes” University of Medicine and Pharmacy, Timisoara,

Romania

${ }^{3}$ Department of Cardiology, Erasme Hospital, Université Libre de Bruxelles, Belgium

${ }^{4}$ Department of Cardiology, Rouen University Hospital, Rouen, France
}

blications on this subject have been scarce, and ablative treatment very effective, the electrophysiology community accommodated with classical knowledge about the isthmus dependent AFL. Even if some of this knowledge is now challenged ${ }^{5}$, ablation at the level of the cavo-tricuspid isthmus remains the cornerstone of typical AFL ablation'.

Literature data suggests similar or even better catheter contact on caval regions of the cavo-tricuspid isthmus $(\mathrm{CTI})^{7}$. Yet $\mathrm{CTI}$ ablation can be challenging 
owing to instability at the inferior vena cava (IVC) edge. No study specifically addressed the issue of catheter-tissue contact on caval/mid/annular regions of the CTI.

\section{METHODS}

Patients scheduled for typical atrial flutter ablation with a contact force sensing catheter (Tacticath 75, Endosense) in our center (Centre Hospitalier Princesse Grace, Monaco) were prospectively included. The study was approved by the institutional committee on human research. According to institutional guidelines all patients were informed and gave their written consent for the invasive procedures and the study. Antiarrhythmic drugs were withdrawn at least five half-lives before the procedures (except amiodarone, interrupted one month before).

All procedures were performed with an uninterrupted anticoagulation regimen: vitamin $\mathrm{K}$ antagonists with a 2 to 3 International Normalized Ratio or direct oral anticoagulants with the last administration of the drug 12 (for dabigatran and apixaban) or 12 to 24 (for rivaroxaban) hours before the procedure.

Ablation procedures have been performed in a fasting state, under local anesthesia and mild intravenous sedation (midazolam I to $2 \mathrm{mg}$ ). During RF delivery, pain control was obtained by intravenous I to $3 \mathrm{mg}$ of nalbuphine. By an echo guided right femoral venous approach were inserted: a decapolar halo catheter (Inquiry H, Irvine Biomedical Inc., Irvine, CA; IBI) placed on the tricuspid annulus with its distal tip in the antero-inferior right atrium and a large-curve steerable 3.5-mm-irrigated-tip CF ablation catheter (Tacticath 75). A minority of patients, at the operator's discretion, had coronary sinus (CS) catheterization with a decapolar diagnostic catheter (Inquiry ${ }^{\text {TM }}$ L, 2-5-2 mm spacing, Saint Jude Medical-SJM).
Nonhomogeneous force application during typical flutter ablation

Operators aimed at optimizing CF (e.g. > $10 \mathrm{~g}$ ) for all RF pulses. If necessary, a steerable sheath was used for the ablation catheter (Agilis, SJM). Most often, CF varies with cardiac cycle and respiratory movements (Figure I); this variation is integrated in a more powerful contact parameter - the force-time integral (FTI).

Electrograms were acquired on a digital electrophysiological recording system (Prucka Engineering, Inc., Houston, TX, USA), with a sampling rate of $\mathrm{I} \mathrm{kHz}$. Bipolar signals were recorded with a 30 to $500 \mathrm{~Hz}$ filtering and a $50 \mathrm{~Hz}$ notch pass. Morphological analysis and measurements of the bipolar EGM on the distal poles of the ablation catheter were performed simultaneously after the procedure by two electrophysiologists. Amplification and display speed were optimized. Poor quality EGMs, mainly due to artifacts, were excluded from the final analysis.

Each CTI line was divided in 3 segments (Figure 2): annular CTI (next to the tricuspid valve), mid CTI (in the middle of the cavo-tricuspid isthmus) and the caval

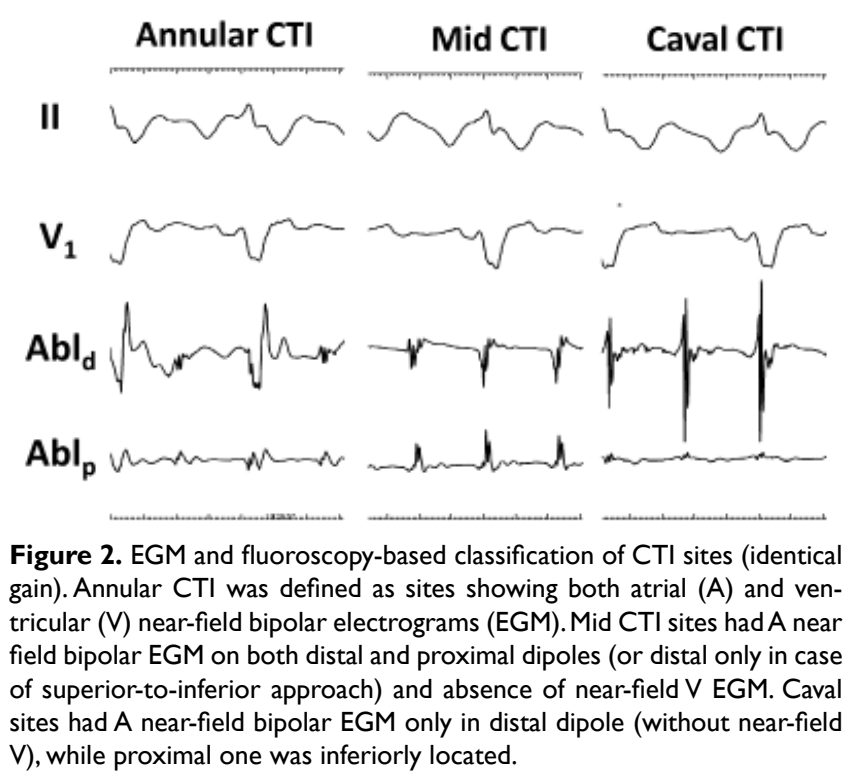

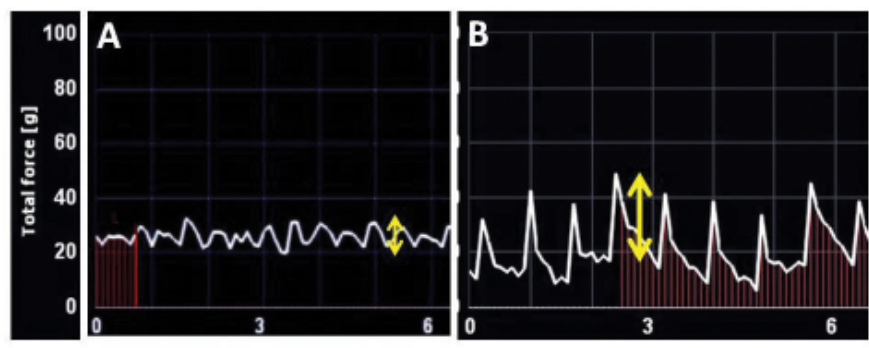
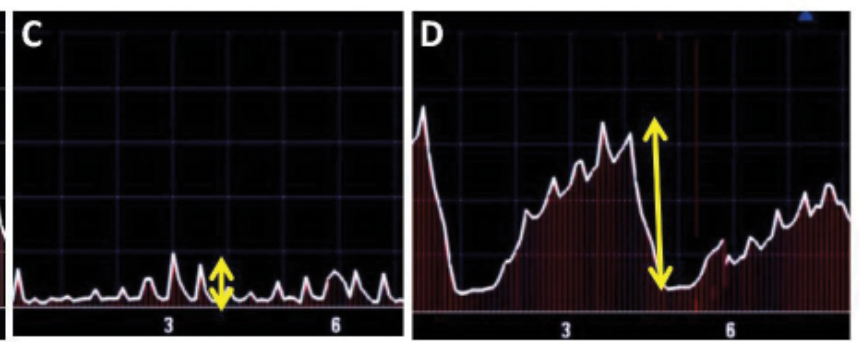

Figure I. Contact force (CF) variability with cardiac cycle and with respiratory movements. (A) good contact, (B) variable contact, (C) poor contact, (D) respiratory variations. Dynamic range is depicted (yellow arrows). 
CTI (posteriorly located). Annular CTI was defined as sites showing both atrial $(A)$ and ventricular $(V)$ nearfield bipolar electrograms (EGM). Mid CTI sites had A near field bipolar EGM on both distal and proximal dipoles (or distal only in case of superior-to-inferior approach). Caval sites had near-field bipolar EGM only in distal dipole, while proximal one was inferiorly located.

RF was delivered with a Stockert 70 generator (BW) with a $42^{\circ} \mathrm{C}$ target temperature. Power setting was adjusted between 20 and $35 \mathrm{~W}$. The catheter was continuously irrigated at 17 (for power $\leq 30 \mathrm{~W}$ ) to $30 \mathrm{ml} / \mathrm{min}$ (for a power setting of $35 \mathrm{~W}$ ) with $0.9 \%$ $\mathrm{NaCl}$. Duration of each RF application was left to the operator's appreciation, aiming at an FTI of 700 gs.3 Care was taken to perform ablation in a point-bypoint manner for 20 to $30 \mathrm{~s}$. Successful ablation was defined by completion of bidirectional CTI block (clockwise block proven by anterior right atrium activation sequence during septal CTI pacing) with a waiting time of 30 minutes.

\section{Statistical analysis}

Continuous variables are expressed as mean \pm SD. Numerical variables were compared with the t-test or the Mann-Whitney-Wilcoxon test (in case of nonnormality). Nominal variables were compared using of the chi-squared test or Fisher's exact, as appropriate. Simultaneous multiple comparisons were performed using ANOVA. $\mathrm{P}<0.05$ was considered significant.

\section{RESULTS}

Twenty-seven patients (22 men, 67 12 years) were included. Complete persistent (at $30 \mathrm{~min}$ ) CTI block

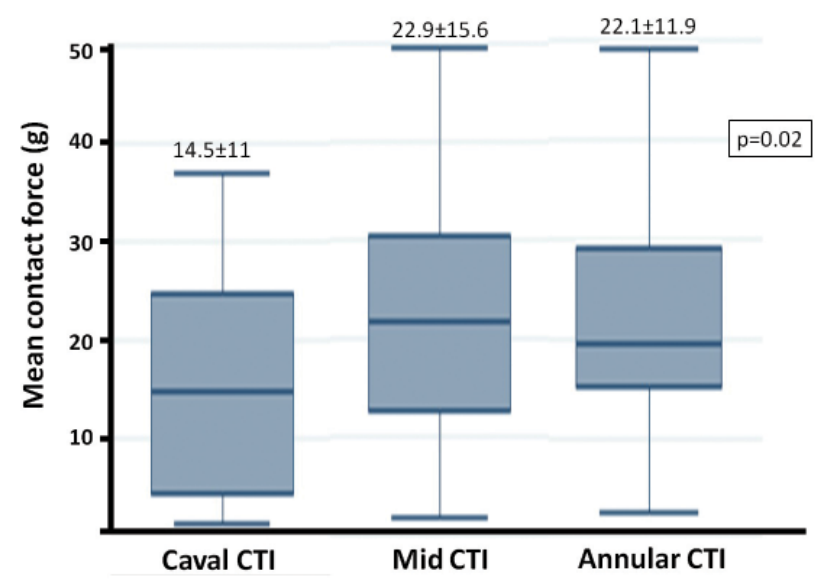

Figure 3. Mean contact force (g) over the entire duration of each RF pulse for the 3 predefined CTI regions. was obtained in all patients. A steerable sheath was used in 12 pts (44\%), mainly due to the impossibility of reaching the anterior aspect of the $\mathrm{CTI}$ without the sheath. Overall procedure duration was $93 \pm 30$ minutes, RF delivery time $10 \pm 6 \mathrm{~min}$, fluoroscopy time $14 \pm 8$ min. Mean CF was I5.8 $\pm 5.9 \mathrm{~g}$.

In a subset of patients $(n=8)$, all RF lesions were analyzed. For the I42 analyzed RF applications, contact parameters by site are depicted in the Table I. Despite contact optimization, CF at beginning of RF (including its lateral and axial components) was significantly lower at caval CTI than at the mid CTI and annular CTI. Mean CF (for the entire RF pulses) was also lower at caval CTI (Figure 3). CF and FTI were higher during sinus rhythm than during flutter $(23.2 \pm 15.3$ vs $18.5 \pm 15.4 \mathrm{~g}, \mathrm{p}=0.04$ and $677 \pm 432$ vs $532 \pm 357 \mathrm{gs}, p=0.03)$. Use of a sheath improved mean CF $(24.4 \pm 12.5$ vs $18.4 \pm \mid 4.9 \mathrm{~g}, \mathrm{p}=0.0 \mathrm{I})$ but this did not reach statistical significance at caval sites $(17.5 \pm \mathrm{I} \mathrm{I} .4 \mathrm{vs}$ $12.6 \pm \mid 0.7 \mathrm{~g}, \mathrm{P}=0.3 \mathrm{I})$.

\section{DISCUSSION}

\section{Main findings}

We found that despite the operator's efforts to uniformly optimize contact in all CTI regions, CF was significantly lower at the caval CTI than at mid and annular CTI. CF and FTI were higher during sinus rhythm than during flutter. In difficult cases, the use of a steerable sheath helped reaching the anterior (annular) CTI but also improved mean CF.

\section{CF sensing technologies}

CF catheters have become the gold-standard of radiofrequency ablation nowadays. Three CF sensing catheters with different technologies exist. The Tacticath ${ }^{8}$, a 7-French $3.5 \mathrm{~mm}$ open irrigated tip catheter, has embedded 3 optical fibers which allow measurement of both the magnitude and direction of the CF; this information as well as the force-time integral (FTI) and the lesion-size index ( $\mathrm{LSI}$ ) for each RF application are displayed on a dedicated screen (Tactisys, Endosense) or on the mapping system (Ensite Precision, Abbott). The ThermoCool SmartTouch Catheter (Biosense Webster; BW, Inc., Diamond Bar, California) uses a small spring connecting the ablation tip electrode to the catheter shaft with a magnetic transmitter and sensors to measure microdeflection of the spring ${ }^{9}$. Information like CF, FTI but also the integrative ablation index is directly displayed on the mapping system (Carto 3, BW). The IntellaNav StablePoint catheter (Bos- 


\begin{tabular}{|c|c|c|c|c|}
\hline Parameter & Caval CTI $(n=28)$ & $\begin{array}{l}\text { Mid CTI } \\
(n=76)\end{array}$ & $\begin{array}{c}\text { Annular CTI } \\
(n=38)\end{array}$ & $\mathbf{p}$ \\
\hline CF at beginning of RF (g) & $1 \mathrm{I} .1 \pm 9.7$ & $19.9 \pm 11.8$ & $20 \pm 12.2$ & 0.001 \\
\hline Lateral CF at beginning of RF (g) & $9.4 \pm 9.2$ & $16.8 \pm 10.5$ & $14.1 \pm 9.1$ & 0.004 \\
\hline Axial CF at beginning of RF (g) & $3.2 \pm 5.6$ & $6.8 \pm 9.9$ & $10.6 \pm 12.3$ & 0.01 \\
\hline Dynamic range of CF at the beginning of RF (g) & $12.7 \pm 14.3$ & $13.5 \pm 7$ & $16 \pm 8.7$ & 0.29 \\
\hline Force Time Integral (FTI) (gs) & $378 \pm 285$ & $707 \pm 469$ & $589 \pm 241$ & 0.0008 \\
\hline RF duration $(s)$ & $29.7 \pm 12.8$ & $33.4 \pm 15.4$ & $29.9 \pm 11.1$ & 0.31 \\
\hline Mean CF (g) & $|4.5 \pm 1|$ & $22.9 \pm 15.6$ & $22.1 \pm 11.9$ & 0.02 \\
\hline FTPI (gsW) & $11100 \pm 8214$ & $1859| \pm 1| 407$ & $18117 \pm 7066$ & 0.004 \\
\hline
\end{tabular}

ton Scientific) combines the microinductive method of measuring force with a spring and the assessment of the catheter-tissue electrical coupling by means of the measurement of the local (bipolar) impedance and is at the dawn of its clinical use ${ }^{10}$.

\section{Results in perspective}

Obtaining an optimal CF is commonly considered as dependent on operator skills. If respiratory and cardiac cycle variations of CF are obvious and have been documented in the literature ${ }^{7}$ the anatomical dependence of CF is less known. Kumar et $\mathrm{al}^{7}$ reported in a 15 patients group undergoing CTI ablation similar or higher CF at the caval CTI when compared with mid and annular CTI, irrespective of ventilation (apnea or not). In their study, the CTI was divided into 3 equidistant segments (annular, mid, and caval) for the purpose of data analysis. This allowed region specific assessment of CF but is very different from the segmentation in our study, based on EGM interpretation, and closer to what operators may encounter in clinical practice. Indeed, purely caval CTI is the posterior CTI with a downslope favoring inferior catheter dislodgement when a higher pressure in applied. This is why, in our opinion, a stable position of the ablation catheter in this part of the CTI is only obtained with a lower CF. Alternately, the use of a sheath might provide a support preventing catheter dislodgement for increased CF.

This phenomenon is also encountered in other atrial and ventricular particular regions. Tissue distortion created by increased CF leads to catheter dislodgement and instability, limiting CF in regions like carina (inter venous ridge between ipsilateral pulmonary veins ${ }^{7}$, but also anterior segment of the left pulmonary veins at the level of the ridge between left PV and left atrial appendage or at papillary muscles in the left ventricle. Beyond the use of a steerable sheath, to improve stability, cryotherapy has been proposed to overcome this technical limitation".
Another anatomical factor may play a role limiting the CF at the caval CTI: the existence of a prominent Eustachian valve/ridge. Moreover, a distinct subeustachian pouch was documented in up to $32 \%$ of patients in anatomical studies, most often located at the posterior and middle istmus ${ }^{12}$. In many cases, the Eustachian valve and ridge form a line of conduction block between the inferior vena cava (IVC) and the coronary sinus (CS) ostium ${ }^{13}$. The electrophysiological implications with the corresponding variants of typical atrial flutters have been discussed elsewhere ${ }^{14}$.

\section{CONCLUSION}

Applied forces are significantly lower at the IVC edge during CTI ablation. This supports the use of a steerable sheath in challenging cases.

\section{Conflict of interest: none declared.}

\section{References}

I. Yokoyama K, Nakagawa H, Shah DC, Lambert H, Leo G, Aeby N, Ikeda A, Pitha JV, Sharma T, Lazzara R, Jackman WM. Novel contact force sensor incorporated in irrigated radiofrequency ablation catheter predicts lesion size and incidence of steam pop and thrombus. Circ Arrhythm Electrophysiol. 2008; I:354-362

2. Thiagalingam A, D'Avila A, Foley L, Guerrero JL, Lambert H, Leo G, Ruskin JN, Reddy VY. Importance of catheter contact force during irrigated radiofrequency ablation: Evaluation in a porcine ex vivo model using a force-sensing catheter. J Cardiovasc Electrophysiol. 2010;21:806-81।

3. Squara F, Latcu DG, Massaad Y, Mahjoub M, Bun SS, Saoudi N. Contact force and force-time integral in atrial radiofrequency ablation predict transmurality of lesions. Europace. 20|4; I6:660-667

4. Taghji P, El Haddad M, Phlips T, Wolf M, Knecht S, Vandekerckhove $Y$, Tavernier R, Nakagawa H, Duytschaever M. Evaluation of a strategy aiming to enclose the pulmonary veins with contiguous and optimized radiofrequency lesions in paroxysmal atrial fibrillation: A pilot study. JACC. Clinical electrophysiology. 2018;4:99-108

5. Lațcu DG, Saoudi N. Typical flutter rewritten: From textbooks to ultra-high-definition mapping. JACC. Clinical electrophysiology. 2017; 3:987-990

6. Saoudi N, Mouton-Schleiffer D, Letac B. Direct catheter fulguration of atrial flutter. Lancet. 1987;2:568-569

7. Kumar S, Morton JB, Halloran K, Spence SJ, Lee G, Wong MC, Kistler PM, Kalman JM. Effect of respiration on catheter-tissue contact force during ablation of atrial arrhythmias. Heart Rhythm. 2012;9: |04 I-I047 el04 I 
8. Reddy VY, Shah D, Kautzner J, Schmidt B, Saoudi N, Herrera C, Jaïs P, Hindricks G, Peichl P, Yulzari A, Lambert H, Neuzil P, Natale A, Kuck $\mathrm{KH}$. The relationship between contact force and clinical outcome during radiofrequency catheter ablation of atrial fibrillation in the toccata study. Heart Rhythm. 2012;9:I789-I795

9. Natale A, Reddy VY, Monir G, Wilber DJ, Lindsay BD, McElderry HT, Kantipudi C, Mansour MC, Melby DP, Packer DL, Nakagawa H, Zhang B, Stagg RB, Boo LM, Marchlinski FE. Paroxysmal af catheter ablation with a contact force sensing catheter: Results of the prospective, multicenter smart-af trial. J Am Coll Cardiol. 2014;64:647656

10. Garrott K, Laughner J, Gutbrod S, Sugrue A, Shuros A, Sulkin M, Yasin O, Bush J, Pottinger N, Meyers J, Kapa S. Combined local impedance and contact force for radiofrequency ablation assessment. Heart Rhythm. 2020; 17:137|-1380

II. Gordon JP, Liang JJ, Pathak RK, Zado ES, Garcia FC, Hutchinson MD, Santangeli P, Schaller RD, Frankel DS, Marchlinski FE, Supple GE. Percutaneous cryoablation for papillary muscle ventricular arrhythmias after failed radiofrequency catheter ablation. J Cardiovasc Electrophysiol. 2018;29:1654-1663
12. Hisazaki K, Kaseno K, Miyazaki S, Amaya N, Hasegawa K, Shiomi Y, Tama N, Ikeda H, Fukuoka Y, Morishita T, Ishida K, Uzui H, Tada H. Intra-procedural evaluation of the cavo-tricuspid isthmus anatomy with different techniques: Comparison of angiography and intracardiac echocardiography. Heart and vessels. 2019;34:I703-I709

13. Nakagawa H, Lazzara R, Khastgir T, Beckman KJ, McClelland JH, Imai S, Pitha JV, Becker AE, Arruda M, Gonzalez MD, Widman LE, Rome M, Neuhauser J, Wang X, Calame JD, Goudeau MD, Jackman WM. Role of the tricuspid annulus and the eustachian valve/ridge on atria flutter. Relevance to catheter ablation of the septal isthmus and a new technique for rapid identification of ablation success. Circulation. 1996;94:407-424

14. ECG-Based Origin of Atrial Flutter. Lațcu DG, Saoudi N, Marchlinski FE. Handbook of Cardiac Electrophysiology 2nd Edition, edited ByAndrea Natale, Oussama M. Wazni, Kalyanam Shivkumar, Francis E. Marchlinski, Taylor and Francis Group 2020: Chapter 32; https://doi. org/10.1201/978I315II8086. 